\title{
Sequential transplantation of exosomes and mesenchymal stem cells pretreated with a combination of hypoxia and Tongxinluo efficiently facilitates cardiac repair
}

\author{
Yuyan Xiong ${ }^{\dagger}$, Ruijie Tang ${ }^{\dagger}$, Junyan Xu, Wenyang Jiang, Zhaoting Gong, Lili Zhang, Xiaosong Li, Yu Ning, \\ Peisen Huang, Jun Xu, Guihao Chen, Chen Jin, Xiangdong Li, Haiyan Qian and Yuejin Yang * (1)
}

\begin{abstract}
Background: Bone marrow-derived mesenchymal stem cells (MSCs), which possess immunomodulatory characteristic, are promising candidates for the treatment of acute myocardial infarction (AMI). However, the low retention and survival rate of MSCs in the ischemic heart limit their therapeutic efficacy. Strategies either modifying MSCs or alleviating the inflammatory environment, which facilitates the recruitment and survival of the engrafted MSCs, may solve the problem. Thus, we aimed to explore the therapeutic efficacy of sequential transplantation of exosomes and combinatorial pretreated MSCs in the treatment of AMI.

Methods: Exosomes derived from MSCs were delivered to infarcted hearts through intramyocardial injection followed by the intravenous infusion of differentially pretreated MSCs on Day 3 post-AMI. Enzyme linked immunosorbent assay (ELISA) was performed to evaluate the inflammation level as well as the SDF-1 levels in the infarcted border zone of the heart. Echocardiography and histological analysis were performed to assess cardiac function, infarct size, collagen area and angiogenesis.

Results: Sequential transplantation of exosomes and the combinatorial pretreated MSCs significantly facilitated cardiac repair compared to AMI rats treated with exosomes alone. Notably, compared to the other three methods of cotransplantation, combinatorial pretreatment with hypoxia and Tongxinluo (TXL) markedly enhanced the CXCR4 level of MSCs and promoted recruitment, which resulted in better cardiac function, smaller infarct size and enhanced angiogenesis. We further demonstrated that exosomes effectively reduced apoptosis in MSCs in vitro.

Conclusion: Sequential delivery of exosomes and pretreated MSCs facilitated cardiac repair post-AMI, and combined pretreatment with hypoxia and TXL better enhanced the cardioprotective effects. This method provides new insight into the clinical translation of stem cell-based therapy for AMI.
\end{abstract}

Keywords: Exosome, MSC, SDF-1, CXCR4, Myocardial infarction

*Correspondence: yangyuejin@fuwai.com; yangyjfw@126.com

†Yuyan Xiong and Ruijie Tang have contributed equally to this study State Key Laboratory of Cardiovascular Disease, Department

of Cardiology, Fuwai Hospital, National Center for Cardiovascular Diseases, Chinese Academy of Medical Science and Peking Union Medical College, Beijing 100037, China

\section{Background}

Cardiovascular disease (CVD), including acute myocardial infarction (AMI), remains the leading cause of morbidity and mortality worldwide [1-3]. Myocardial infarction injury triggers sudden extensive cardiomyocytes loss accompanied by an intense inflammatory original author(s) and the source, provide a link to the Creative Commons licence, and indicate if changes were made. The images or other third party material in this article are included in the article's Creative Commons licence, unless indicated otherwise in a credit line to the material. If material is not included in the article's Creative Commons licence and your intended use is not permitted by statutory regulation or exceeds the permitted use, you will need to obtain permission directly from the copyright holder. To view a copy of this licence, visit http://creativecommons.org/licenses/by/4.0/. The Creative Commons Public Domain Dedication waiver (http://creativeco mmons.org/publicdomain/zero/1.0/) applies to the data made available in this article, unless otherwise stated in a credit line to the data. 
response, which might lead to deteriorated cardiac function, post-infarction remodeling and heart failure $[4,5]$. Stem cell-based therapy is considered a promising strategy for facilitating cardiac repair [6-8], and bone marrow-derived mesenchymal stem cells (MSCs) are ideal candidates due to their immunomodulatory characteristics [9-11]. However, the low retention and poor survival of the transplanted MSCs in the ischemic heart limit their therapeutic efficacy $[12,13]$. Thus, methods either modifying MSCs, or alleviating the inflammatory environment which facilitates the recruitment and survival of MSCs, may solve the problem [14-16].

The stromal cell-derived factor 1 (SDF-1)/CXC chemokine receptor 4 (CXCR4) axis plays pivotal role in facilitating cardiac repair and the recruitment of stem cells to the infarcted myocardium after ischemic injury [17-23]. Myocardial expression of SDF-1 has been confirmed to peak in the early phase of AMI and decrease to a relatively low level in the following days [17, 24, 25]. Therefore, transplantation of MSCs in the early phase may achieve a higher retention rate. However, during the same early stage of AMI, an intense inflammation response occurs and enormous amounts of inflammatory cytokines are released, which is disastrous for transplanted cell survival. Elevating SDF-1 levels while limiting inflammation levels might promote the recruitment and survival of the transplanted cells, thus improving their therapeutic efficacy.

Exosomes, 30-150 nm extracellular vesicles, contain various bioactive proteins and RNAs, and are vital in intercellular communication $[26,27]$. It has been widely reported to exhibit distinct benefits in promoting cardiac recovery via augmenting cell survival [28-31], ameliorating inflammation [32-34], and increasing the myocardial SDF-1 expression level [35] at the early stage in the infarcted heart. In addition, numerous strategies including drug pretreatment [36, 37], hypoxia preconditioning [38, 39], genetic modifications [40-42] and tissue engineering $[43,44]$ have been developed to augment the therapeutic efficacy of MSCs. Among these methods, drug pretreatment such as with stains and Tongxinluo (TXL), as well as hypoxic preconditioning are widely used, which also have potential for clinical translation. TXL, a traditional Chinese medicine compound, is capable of protecting MSCs against hypoxic injury [45]. Additionally, hypoxia preconditioning could augment the therapeutic efficacy of MSCs in myocardial injury treatment $[39,46]$. Whether a combined strategy of hypoxia and TXL pretreatment could better enhance the therapeutic efficacy of MSCs has not been explored yet.

In the present study, we first explored the cardioprotective effects of sequential delivery of exosomes and the combinatorially pretreated MSCs in the treatment of AMI, and further investigated the effects of combined pretreatment with hypoxia and TXL of MSCs. Exosome transplantation in the early stage of AMI ameliorated inflammation, reduced apoptosis and increased myocardial SDF-1, thus creating a better microenvironment for the survival and recruitment of MSCs. Meanwhile, combined pretreatment with hypoxia and TXL enhanced the expression level of CXCR4 and increased the retention rate of MSCs. Sequential transplantation of exosomes and MSCs pretreated with both hypoxia and TXL resulted in better cardiac recovery. Thus, our data suggested that sequential transplantation of exosomes and the pretreated MSCs significantly facilitated cardiac repair, and a combination pretreatment with hypoxia and TXL further augmented the therapeutic efficacy of MSCs, providing novel insights for the clinical treatment of AMI.

\section{Methods \\ Animals}

All animal experiments conformed to the guidelines for animal care and were approved by the Institutional Animal Care and Use Committee of Fuwai Hospital, Chinese Academy of Medical Sciences and Peking Union Medical College.

\section{MSCs isolation and culture}

MSCs were isolated from femoral and tibial bone marrow of male Sprague-Dawley (SD) rats (60-80 g) and cultured in a humidified incubator. Briefly, bone marrow was flushed with Iscove's modified Dulbecco's medium (IMDM, Invitrogen, USA) supplemented with $10 \%$ fetal bovine serum (FBS, Gibco, USA) and 1\% penicillin/streptomycin (Gibco, USA). Flow cytometry was employed to identify MSCs at passage 3 with antibodies against CD90 (eBioscience, USA), CD29 (eBioscience, USA), CD45 (eBioscience, USA), CD11 (BD Bioscience, USA). MSCs at passage 3,4 were used for experiments.

\section{Pretreatment of MSCs}

Ultrafine TXL powder (Shijiazhuang Yiling Pharmaceutical Co., Shijiazhuang, China) was dissolved in serumfree IMDM, and then the suspension was sonicated and centrifuged. Sterile TXL solution was obtained by filtering the supernatant through a $0.22-\mu \mathrm{m}$ filter. The solution was adjusted to a final concentration of $2 \mathrm{mg} / \mathrm{mL}$ by adding IMDM and then stored at $4{ }^{\circ} \mathrm{C}$ or $-20{ }^{\circ} \mathrm{C}$ until use. For TXL pretreatment $\left(\mathrm{MSC}^{\mathrm{T}}\right)$, when passage 3-4 MSCs grew to approximately $60 \%, 400 \mu \mathrm{g} / \mathrm{mL}$ TXL was added to the medium for $24 \mathrm{~h}$. For hypoxia pretreatment $\left(\mathrm{MSC}^{\mathrm{H}}\right)$, when passage 3-4 MSCs grew to approximately $60 \%$, MSCs were cultured in a humidified incubator with $1 \% \mathrm{O}_{2}$ at $37^{\circ} \mathrm{C}$ for $24 \mathrm{~h}$. For combined pretreatment with 
TXL and hypoxia $\left(\mathrm{MSC}^{\mathrm{C}}\right)$, MSCs treated with $400 \mu \mathrm{g} / \mathrm{mL}$ TXL were cultured in a humidified incubator with $1 \% \mathrm{O}_{2}$ at $37^{\circ} \mathrm{C}$ for $24 \mathrm{~h}$.

\section{Exosomes isolation, identification and labeling}

Exosomes were isolated from the conditioned medium of MSCs by differential centrifugation [47]. Briefly, MSCs at passage 3 or 4 were cultivated in IMDM containing 10\% FBS and $1 \%$ penicillin/streptomycin. When grown to 80-90\% confluence, the medium was changed into fresh serum-free IMDM and MSCs were cultured for $48 \mathrm{~h}$. The conditioned supernatants were collected and centrifuged at $300 \mathrm{~g}$ for $10 \mathrm{~min}$ and $2000 \mathrm{~g}$ for $20 \mathrm{~min}$ to eliminate cells and debris. Then, the supernatants were centrifuged at $13,500 \mathrm{~g}$ for $30 \mathrm{~min}$ to remove macrovesicles. The exosomes pellets were obtained by ultracentrifugation at $120,000 \mathrm{~g}$ for $70 \mathrm{~min}$ at $4{ }^{\circ} \mathrm{C}$, washed in phosphate-buffered saline (PBS, pH 7.4, Gibco, USA) and collected by a second ultracentrifugation at $120,000 \mathrm{~g}$ for $70 \mathrm{~min}$. The exosomes were finally resuspended in PBS and stored at $-80^{\circ} \mathrm{C}$ for use.

A microBCA protein assay kit (Thermo Scientific, USA) was utilized to measure the protein concentrations of exosomes. The shapes and sizes of exosomes were determined by transmission electron microscopy (TEM, FEI, Tecnai G2 Spirit BioTwin, USA) and nanoparticle tracking analysis (NTA, PARTICLE METRIX, ZetaVIEW, Germany). Besides, western blotting was used to identify the exosomal markers including Alix (Cell Signaling Technology, USA) and TSG101 (Santa Cruz, USA).

For assessment of uptake and distribution of purified exosomes, exosomes were labeled using PKH26 or PKH67 Fluorescent Cell Linker Kit (Sigma-Aldrich, USA) following the manufacturer's instructions.

\section{Rat AMI model induction}

All surgeries and relevant analyses were performed in a blinded manner. Female SD rats (200-220 g weight) were anesthetized by intraperitoneal injection of pentobarbital sodium $(50 \mathrm{mg} / \mathrm{kg})$ before the surgical procedure. The rats were given ibuprofen at a dose of $30 \mathrm{mg} / \mathrm{kg}$ by gavage at least $12 \mathrm{~h}$ prior to thoracotomy to alleviate preoperative pain and distress. To induce AMI model, the chest was opened gently by left thoracotomy and rats were subjected to the left anterior descending (LAD) coronary artery ligation by a 6-0 silk polyester. Rats were randomized into following groups: Sham group, AMI group (PBS alone), Exo group (exosome treatment alone), MSC group (MSCs treatment alone), Exo + MSC group (Exo combined with MSCs), Exo $+\mathrm{MSC}^{\mathrm{H}}$ group (Exo combined with $\mathrm{MSC}^{\mathrm{H}}$ ), Exo $+\mathrm{MSC}^{\mathrm{T}}$ group (Exo combined with $\mathrm{MSC}^{\mathrm{T}}$ ) and Exo $+\mathrm{MSC}^{\mathrm{C}}$ group (Exo combined with $\mathrm{MSC}^{\mathrm{C}}$ ). The rats in Sham group only underwent the same procedure without LAD ligation. PBS $(100 \mu \mathrm{L})$ or exosomes $(20 \mu \mathrm{g}$, in $100 \mu \mathrm{L}$ PBS) were injected by a 31-gauge Hamilton syringe at three sites around the periinfarcted myocardium $30 \mathrm{~min}$ after LAD ligation. For the following MSC delivery, $2 \times 10^{6} \mathrm{MSC}, \mathrm{MSC}^{\mathrm{H}}, \mathrm{MSC}^{\mathrm{T}}$, or $\mathrm{MSC}^{\mathrm{C}}$ were injected into the Exo-treated rats via the tail vein at Day 3 postinfarction. After operation, the incisions were sewn up and disinfected, followed by postoperative analgesia with ibuprofen for 1 week [48].

\section{Cardiac function by echocardiography}

All measurements and analyses were performed by an experienced investigator in a blind manner. Cardiac function at baseline (Day 3 after AMI) and the endpoint (4 weeks after AMI) were evaluated by transthoracic echocardiography using a VisualSonics Vevo 2100 system. Briefly, rats were anesthetized by $2 \%$ isoflurane in the induction chamber and then a nose cone was placed to maintain sedation level. Rats were placed on a heating pad, keeping the core body temperature $\sim 37^{\circ} \mathrm{C}$ and heart rate $>350$ b.p.m.. M-mode was then used to measure the left ventricular wall thickness and left ventricular inner diameter in systole and diastole. The levels of the left ventricular ejection fraction (LVEF), left ventricular fractional shortening (LVFS), left ventricular end-diastolic volume (LVEDV) and left ventricular end-systolic volume (LVESV) at baseline and the endpoint were measured to assess cardiac function.

\section{Histological analysis}

Four weeks after infarction, rats were euthanized after echocardiography to harvest the hearts. To determine the infarct size and collagen area, hearts were fixed in $4 \%$ paraformaldehyde for $72 \mathrm{~h}$, dehydrated and embedded in paraffin. The heart was cut $1 \mathrm{~mm}$ below the ligation point perpendicular to the axis of the LAD. Masson trichrome and Sirius red staining were utilized to measure the infarct size and collagen area respectively. The infarct size was calculated as [epicardial infarct ratio + endocardial infarct ratio) $/ 2] \times 100$. The epicardial infarct ratio was obtained by dividing the epicardial infarct length by the epicardial circumferences. The endocardial infarct ratio was calculated similarly. Percent area of collagen was calculated as the average ratio of the collagen area to the total area of LV (collagen area/total LV area $\times 100 \%$ ).

\section{Terminal deoxynucleotidyl transferase-mediated dUTP nick-end labeling (TUNEL) assay}

An In Situ Cell Death Detection kit (Roche, Germany) was used to assess apoptotic cells in the ischemic myocardium following the manufacturer's protocols. Briefly, the sections were blocked and incubated with TUNEL reaction mixture for $1 \mathrm{~h}$ at room temperature. 
Then the sections were stained with cardiac troponin $\mathrm{T}$ (cTNT, Abcam, 1:200, USA) at $4{ }^{\circ} \mathrm{C}$ overnight, and nuclei were stained with DAPI. The stained sections were examined under a confocal microscope at $400 \times$ magnification in four randomly chosen fields. Normal nuclei are presented in blue color, and apoptotic nuclei are presented in green. The apoptotic ratio is described as the percentage of apoptotic cells among all cells.

\section{Immunofluorescence staining}

For immunofluorescence staining, the paraffin sections were incubated with primary antibodies at $4{ }^{\circ} \mathrm{C}$ overnight followed by incubation with goat anti-mouse (Thermo Fisher Scientific, 1:200, USA) or goat anti-rabbit (Thermo Fisher Scientific, 1:200, USA) highly crossadsorbed Alexa Fluor 488 or 594 secondary antibodies at room temperature for $1 \mathrm{~h}$. After washed by PBS, sections were stained with DAPI and then observed under a laser scanning confocal microscope (Leica, Germany). Five high-power fields (HPF) per tissue were randomly selected for analysis. Arteriole density and vascular density were reflected by $\alpha$-smooth muscle actin $(\alpha-S M A$, Abcam, 1:200, USA) and CD31 (Abcam, 1:300, USA) staining respectively. Arteriole density or vascular density was calculated as the number of $\alpha-\mathrm{SMA}^{+}$ cells or CD $31^{+}$cells per HPF.

\section{Enzyme linked immunosorbent assay (ELISA) analyses}

Rat SDF-1 ELISA kit (elabscience, China, E-EL-R0922c), rat tumor necrosis factor (TNF)- $\alpha$ and rat interleukin (IL)-6 ELISA kits (eBioscience, USA, BMS625 and BMS622) were used to quantify the expression level of SDF-1 and inflammatory cytokines TNF- $\alpha$ and IL- 6 in the peri-infarcted myocardium at Day1, Day3 and Day7 post-AMI. Heart tissue homogenates were prepared and the following procedures were performed according to the manufacturer's instructions.

\section{Apoptosis determination by flow cytometry}

After pretreated with exosomes for $24 \mathrm{~h}$, MSCs were exposed to hypoxia and serum deprivation (H/SD) conditions. An Annexin V-FITC/PI Kit (Becton, Dickinson and Company, USA) was utilized to evaluate the apoptotic MSCs according to the manufacturer's protocols. Viable MSCs were defined as Annexin $\mathrm{V}^{-} / \mathrm{PI}^{-}$, early apoptotic MSCs as Annexin $\mathrm{V}^{+} / \mathrm{PI}^{-}$and late apoptotic and necrotic MSCs as Annexin $\mathrm{V}^{+} / \mathrm{PI}^{+}$. The proportion of apoptotic MSCs was calculated after adding the number of early and late apoptotic cells together.

\section{Quantitative real-time polymerase chain reaction (qRT-PCR)}

TRIzol reagent (Life Technologies, USA) was used to extract total RNA from MSCs following the manufacturer's instructions. A Prime-Script ${ }^{\mathrm{TM}} \mathrm{RT}$ Reagent Kit with gDNA Eraser (Takara, Japan) was used to perform mRNA reverse transcription. Quantitative real-time PCR was conducted with PowerUp ${ }^{\mathrm{TM}}$ SYBR $^{\mathrm{TM}}$ Green Master Mix (Applied Biosystems, USA) on a QuantStudio 3 Real-Time PCR system (Applied Biosystems, USA). The expression level of mRNA was normalized to $\beta$-actin, and the data were calculated via comparative $2^{-\Delta \Delta \mathrm{Ct}}$ methods. mRNA primer sequences were synthesized by TianyBiotech and listed as follows: $\beta$-actin: Forward: $5^{\prime}-$ CCC GCGAGTACAACCTTCTT-3', Reverse: 5'-CGCAGC GATATCGTCATCCA-3'; CXCR4: Forward: 5'-TTCCTC GGGGCCAAATTCAA-3', Reverse: 5'-GTGGAGACG GAAGAGTGTCC- $3^{\prime}$. Each experiment included 3 technical replicates and at least 3 independent repeats.

\section{Western blotting}

Exosomes and MSCs were collected and then lysed in RIPA lysis buffer (Thermo Fisher Scientific, USA) with a protease inhibitor cocktail (Roche, Germany), and protein concentrations were quantified by BCA protein assay (Beyotime, China). Proteins $(20 \mu \mathrm{g})$ were loaded with $4 \times$ loading buffer, separated on a $4-12 \%$ Bis-Tris gel (Invitrogen, USA) and transferred onto PVDF membranes (Millipore, USA). Then, the membrane was blocked with $5 \%$ bovine serum albumin or skim milk in TBST for $2 \mathrm{~h}$ and incubated with primary antibodies against TSG101 (Santa Cruz Biotechnology, 1:1000, USA), Alix (Cell Signaling Technology, 1:1000, USA), CXCR4 (Proteintech, 1:1000, China) and $\beta$-actin (Cell Signaling Technology, 1:2000, USA) at $4{ }^{\circ} \mathrm{C}$ overnight. After incubated with the corresponding secondary antibodies (Beyotime, 1:3000, China) for $1 \mathrm{~h}$ at room temperature, protein bands were detected with chemiluminescence imaging system (Tanno-5800multi, China). The density of the target bands was normalized to that of $\beta$-actin.

\section{Statistical analysis}

Statistical data are presented as the mean \pm standard error of the mean (SEM) and were analyzed using GraphPad 8.0 (GraphPad Software, USA). Normal distribution was determined by Shapiro-Wilk test. The difference of normal variates was tested by Student's $t$ test within two groups. One-way ANOVA test followed by Tukey post hoc test (variance homogeneity) or Dunnett's T3 test (variance non-homogeneity) was used for multiple comparisons (three or more groups). Non-normal data were analyzed by Mann-Whitney test or Kruskal-Wallis test 
with a Dunn post-test was used for multiple comparisons (three or more groups) with normally distributed variables. Statistical significance was set at $p<0.05$ for all comparisons.

\section{Results}

Identification of exosomes derived from MSCs

MSCs at passage 3 were typically adherent spindleshaped cells and were identified by flow cytometry as exhibiting $\mathrm{CD} 90^{+}, \mathrm{CD} 29^{+}, \mathrm{CD} 45^{-}$and $\mathrm{CD} 11^{-}$expression (Fig. 1A). TEM and NTA were used to identify the shape and size of MSCs-derived exosomes, which were typically cup-shaped with an average size of $121.6 \mathrm{~nm}$ (Fig. 1B, C). Western blot analysis indicated that the isolated exosomes expressed exosome-specific proteins such as Alix and TSG101 (Fig. 1D).

\section{Exosome delivery reduced inflammation and apoptosis and elevated myocardial SDF-1 levels}

We first injected PBS $(100 \mu \mathrm{L})$ or PKH26-labeled exosomes $(20 \mu \mathrm{g}$, in $100 \mu \mathrm{L}$ PBS) into the peri-infarcted myocardium 30 min post-AMI. Exosome delivery significantly reduced inflammatory cytokines levels compared to levels in the AMI group, as indicated by the ELISA results for TNF- $\alpha$ and IL-6 (Fig. 1E, F). Consistent with previous reports $[35,36]$, the ELISA results showed that SDF-1 levels in peri-infarcted myocardium in the AMI group peaked at Day 1 postinfarction and then rapidly declined to a low level within the first week. Conversely, exosome delivery enhanced SDF-1 levels and maintained it at a relatively high level on Day 3, although it decreased to a low level on Day 7 (Fig. 1G). On Day 3 post-AMI, the confocal images indicated that PKH26-labeled exosomes were still retained in myocardium (Fig. $1 \mathrm{H}$ ), and the exosome delivery significantly reduced the number of the apoptotic cells compared to that observed in the AMI group (Fig. 1I, J). To sum up, intramyocardial injection of exosomes resulted in decreased inflammation levels, elevated myocardial SDF-1 expression levels and reduced apoptosis in infarcted border zone on Day 3 postinfarction, making it an appropriate time for MSCs transplantation. Thus, we chose Day 3 postinfarction to deliver the MSCs to evaluate the effects of combined pretreatment in modulating the therapeutic efficacy of MSCs.

\section{Exosome and the combinatorially pretreated MSC delivery improved cardiac function postinfarction}

To evaluate whether the combinatorially pretreated MSCs exerted better therapeutic efficacy, exosomes were first injected intramyocardially into the peri-infarcted hearts $30 \mathrm{~min}$ after injury, and MSCs (including MSC, $\mathrm{MSC}^{\mathrm{H}}, \mathrm{MSC}^{\mathrm{T}}$, or $\mathrm{MSC}^{\mathrm{C}}$ ) were then injected through the tail vein at Day 3 post-AMI (Fig. 2A). Compared to the
AMI group, the Exo group had significantly ameliorated the AMI-induced LV dilation on Day 28 and co-delivery therapy exerted better effects (Fig. 2B). Marked decreases in LVEF and LVFS were observed in the AMI group, indicating the deteriorated cardiac function. Sequential transplantation of exosomes and MSCs led to a significant elevation in LVEF and LVFS, and the Exo $+\mathrm{MSC}^{\mathrm{C}}$ group showed the highest improvement in cardiac function among all cotransplantation groups (Fig. 2C-F).

\section{Exosomes and combinatorially pretreated MSCs transplantation dramatically ameliorated infarct size and collagen area}

Since exosomes and the combinatorially pretreated MSCs therapy achieved elevated cardiac function, we further evaluated the infarct size and collagen area. The $\mathrm{Exo}+\mathrm{MSC}^{\mathrm{H}}$, Exo $+\mathrm{MSC}^{\mathrm{T}}$ and $\mathrm{Exo}+\mathrm{MSC}^{\mathrm{C}}$ groups achieved a reduced infarct size compared to Exo group at 4 weeks post-AMI. Among the three groups, the Exo + MSC $^{C}$ group exhibited a lower infarct size compared to both the Exo $+\mathrm{MSC}^{\mathrm{H}}$ and Exo $+\mathrm{MSC}^{\mathrm{T}}$ groups (Fig. 3A, B). Similar to the infarct size results, the Exo $+\mathrm{MSC}^{\mathrm{C}}$ group demonstrated the lowest collagen area compared with all the other three cotransplantation groups (Exo $+\mathrm{MSC}$, Exo $+\mathrm{MSC}^{\mathrm{H}}$ and Exo $+\mathrm{MSC}^{\mathrm{T}}$ ) (Fig. 3C, D). Taken together, these results showed that sequential delivery of exosomes and the combinatorial pretreated MSCs led to a reduced infarct size and collagen area, while Exo $+\mathrm{MSC}^{\mathrm{C}}$ might be the best transplantation strategy for the treatment of AMI.

\section{Exosomes and combinatorially pretreated MSCs delivery augmented angiogenesis after AMI}

To evaluate whether exosomes and the combinatorially pretreated MSCs delivery induces morphometric changes in the ischemic heart, we measured the arteriolar and capillary densities by quantification of $\alpha$-SMA staining (Fig. 4A, B) and CD31 staining, respectively (Fig. 4C, D). Exosomes transplantation alone as well as all cotransplantation treatments achieved increased arteriolar and capillary density compared to that observed in the AMI group. Notably, Exo $+\mathrm{MSC}^{\mathrm{C}}$ showed the highest arteriolar and capillary density among all combinatorial treatments.

\section{The combination of hypoxia and TXL pretreatment enhanced the effects of MSCs by increasing CXCR4 levels}

To better elucidate the mechanisms underlying the superior cardioprotective effects observed for Exo $+\mathrm{MSC}^{\mathrm{C}}$, we evaluated the retention rate of the engrafted MSCs in infarcted myocardium via fluorescent dye tracing. The CM-Dil-labeled MSCs were injected through tail vein at Day 3 after the delivery of PKH67-labeled exosomes. 

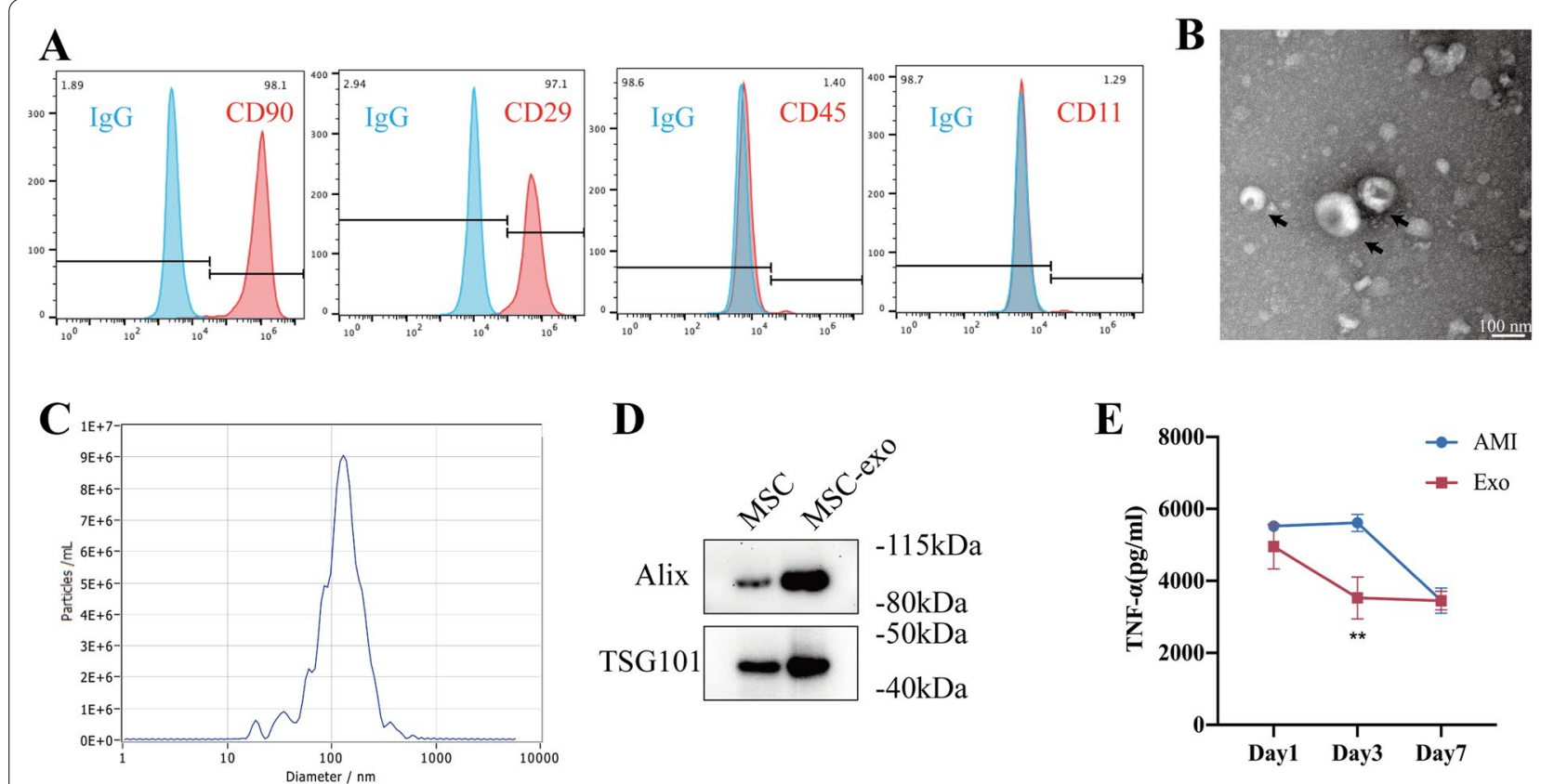

F

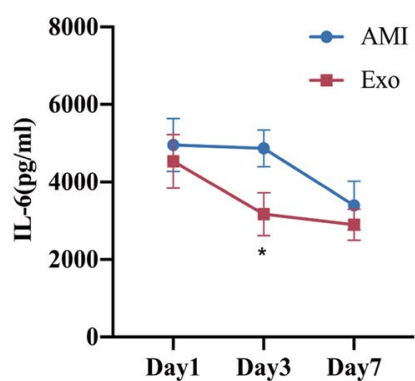

I

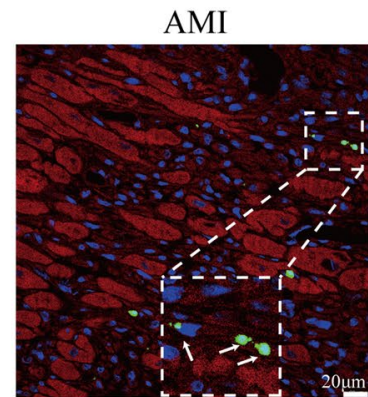

G

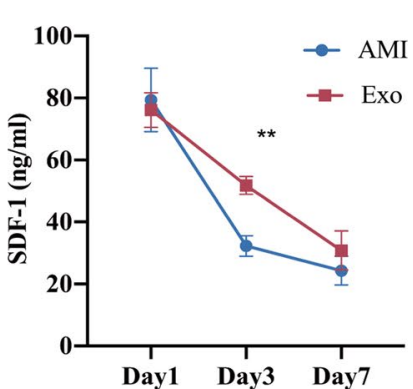

Exo

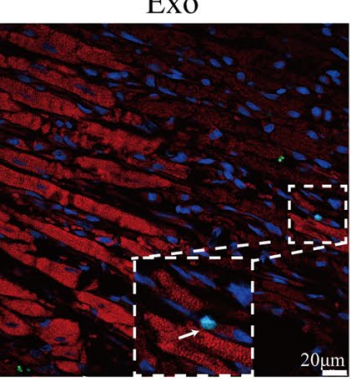

AMI
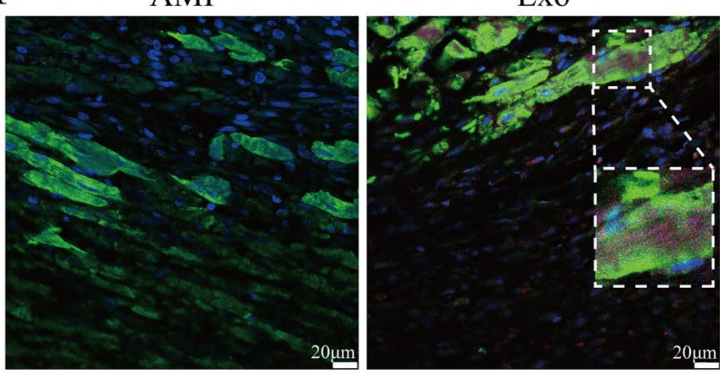

$\mathbf{J}$

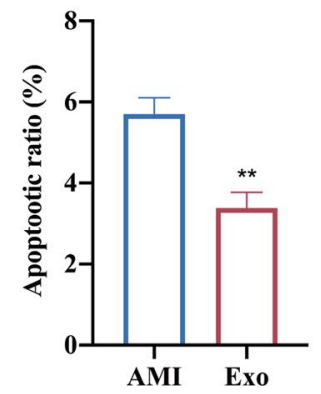

Fig. 1 Characterization of exosomes derived from MSCs and their therapeutic effects. A Flow cytometry of the cell surface markers of MSCs. B Transmission electron microscopy was used to identify the shape of exosomes. Scale bar $=100 \mathrm{~nm}$. C Nanoparticle tracking analysis was utilized to analyze the particle size of exosomes. D Detection of exosomal protein markers was performed using western blotting. Quantification of TNF-a $(\mathbf{E})$ and IL-6 (F) levels in the peri-infarcted myocardium by ELISA $(n=6)$. G Quantification of SDF-1 levels on Day 1, Day 3 and Day 7 postinfarction $(n=5)$. $\mathbf{H}$ Distribution of PKH-26-labeled exosomes in the infarcted heart on Day 3 after AMI. Scale bar $=20 \mu \mathrm{m}$. Representative images $(\mathbf{I})$ and quantification ( $\mathbf{J}$ ) of apoptotic cells in the peri-infarcted myocardium in the AMl or Exo group on Day3 $(n=4)$. All data are shown as the mean \pm SEM. Student's $t$ test or one-way ANOVA followed by Tukey's test was performed to assess statistical significance. ${ }^{*} p<0.05,{ }^{* *} p<0.01$ versus AMl group 


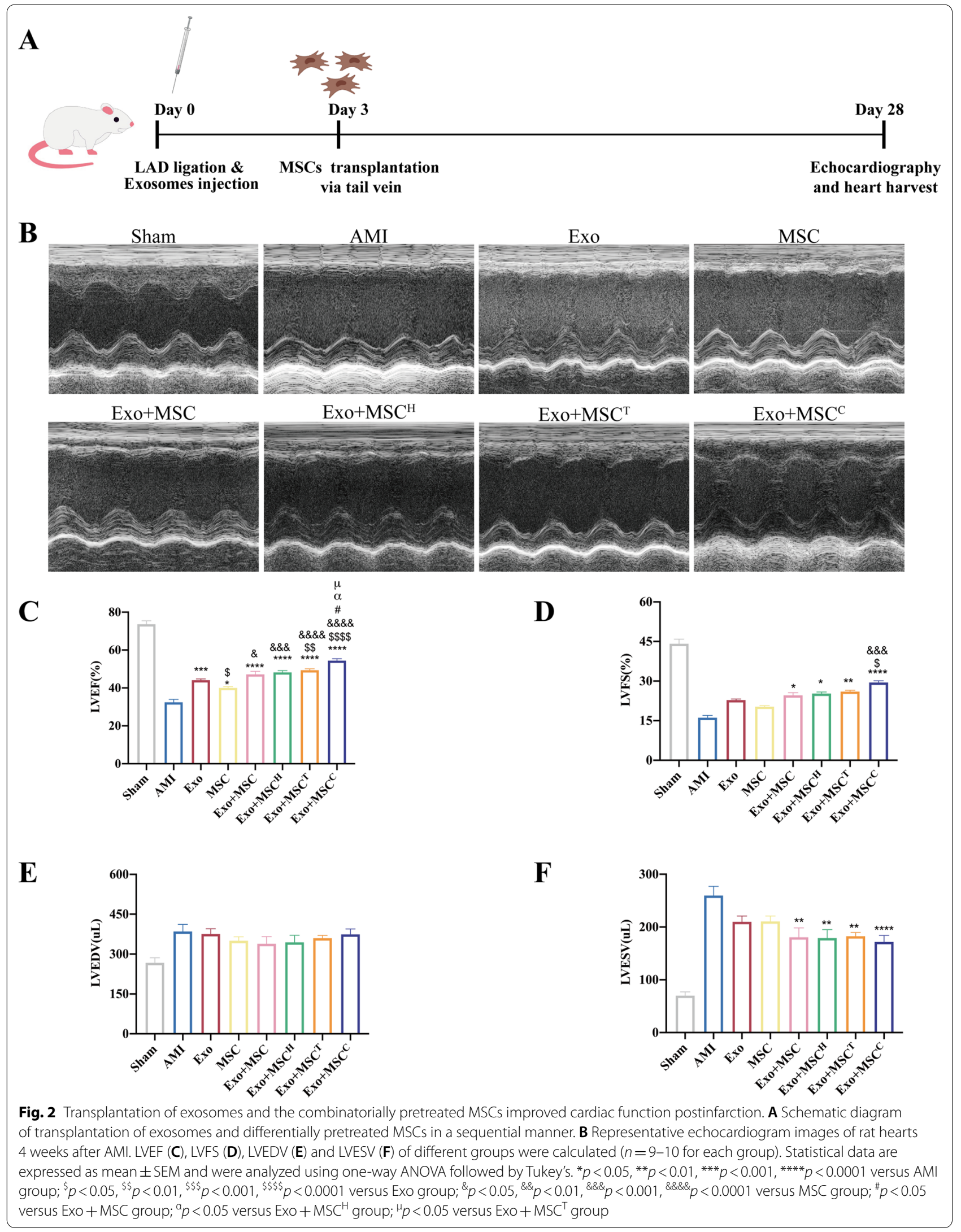


Combined delivery of exosome and MSCs showed higher percentage of CM-Dil ${ }^{+}$cells compared to the single MSC group. And significantly more CM-Dil ${ }^{+}$cells were found in the $\mathrm{Exo}+\mathrm{MSC}^{\mathrm{C}}$ group than in the other combinatorial groups, indicating a higher recruitment rate (Fig. 5A, B). Collectively, these results showed that the combined pretreatment with hypoxia and TXL increased the retention of transplanted MSCs. Since the SDF-1/CXCR4 axis is vital in the recruitment of MSCs to infarcted myocardium [49-51], we further investigated the effects of combinatorial pretreatment on CXCR4 levels in MSCs. Both the mRNA and protein levels of CXCR4 in MSCs were significantly elevated after combined pretreatment with hypoxia and TXL (Fig. 5C-E).

\section{Exosomes protected MSCs against hypoxia-induced apoptosis in vitro}

To further determine the effect of pre-injection of exosomes on the transplanted MSCs, we pretreated MSCs with exosomes for $24 \mathrm{~h}$. PKH-26-labeled exosomes could be taken up by MSCs after $24 \mathrm{~h}$ of incubation (Fig. 5F). As flow cytometry indicated, the Exo group had significantly reduced apoptosis of MSCs compared to the $\mathrm{H} / \mathrm{SD}$ and H/SD + Exo (Ultra) groups, in which exosomes were ruptured by ultrasonication (Fig. 5G, H). In addition, Exo treatment markedly elevated the anti-apoptotic protein $\mathrm{Bcl}-2$ level and decreased the pro-apoptotic cleaved-caspase 3 level of MSCs (Fig. 5I-L) under H/SD conditions. Collectively, these results demonstrated that exosomes efficiently protected MSCs against hypoxiainduced injury.

\section{Discussion}

Although various types of stem cells seem to be promising strategies for facilitating cardiac repair post-ischemic injury, the low retention rate and poor survival of engrafted cells have restricted their therapeutic efficacy in the treatment of AMI $[12,13]$. Exosome transplantation have been demonstrated to ameliorate inflammation and preserve the cardiac function [28-32]. Therefore, we explored whether exosome delivery could ameliorate the harsh microenvironment to facilitate the recruitment and survival of stem cells, and we investigated whether combined pretreatment with hypoxia and TXL could better enhance the effects of the transplanted MSCs. The main findings were as follows: (1) Exosome delivery significantly augmented SDF-1 expression in periinfarcted myocardium, with limited inflammation and reduced apoptosis on Day 3 post-AMI; (2) sequential delivery of MSCs after exosome injection significantly facilitated cardiac repair; and (3) combined pretreatment with hypoxia and TXL increased the CXCR4 level, which augmented the recruitment of transplanted MSCs and achieved the best therapeutic efficacy (Fig. 6).

As a promising cell-free therapy for promoting cardiac repair $[52,53]$, exosomes derived from MSCs have been found to have anti-apoptotic [28, 29, 31], anti-inflammatory [32, 54], as well as pro-angiogenic effects $[55,56]$, all of which are crucial to restore the function of infarcted myocardium. However, the short half-life and mild efficacy limited the therapeutic application of exosomes $[53,57]$. In this study, we demonstrated that early injection of exosomes effectively ameliorated inflammation, reduced apoptosis and enhanced the expression level of SDF-1 at Day 3 post-AMI. In addition, exosome pretreatment effectively protected MSCs against hypoxic injury. Collectively, with reduced inflammation, apoptosis and increased SDF-1 levels, Day 3 post-AMI was an appropriate time for sequential transplantation of MSCs. Zhang et al. pretreated cardiac stem cells (CSCs) with exosomes derived from MSCs (MSC-Exo), and MSC-Exo-preconditioned CSCs significantly enhanced angiogenesis, reduced cardiac fibrosis and elevated cardiac function [58]. Shi et al. also reported that the pretreatment of CSCs with MSC-Exo enhanced the therapeutic effects in ischemic myocardium [59]. Therefore, exosomes derived from MSCs could be used as a new therapeutic vehicle for facilitating stem cell-mediated cardiac repair.

Due to the limited retention and survival rate of MSCs, various strategies have been developed to modify the therapeutic efficacy of MSCs including drug pretreatment [36, 37], hypoxia preconditioning [38, 39], genetic modification [40-42] and tissue engineering [43, 44, 60]. Of note, cell sheet transplantation has turned out to be a novel option in MI therapy, which possesses the advantages of prolonging retention and survival, improving engraftment and prognosis [60-63]. Cell sheets derived from modified MSCs transplantation might provide with novel insights into enhancing therapeutic effects in MI treatment. As reported, hypoxia pretreatment enhanced the expression level of CXCR4 and reduced the apoptosis under hypoxic injury [64-66]. In addition, drug pretreatment, including commonly clinically used TXL, has been demonstrated to protect MSCs against hypoxia-induced injury [45]. Therefore, we chose to combine hypoxia and TXL pretreatment to test whether the cardioprotective effects of MSCs could be enhanced. Four weeks postAMI, MSCs pretreated with hypoxia and TXL achieved the highest retention rate and best performance in cardiac repair. Further analysis indicated that the combined hypoxia and TXL pretreatment significantly upregulated the expression levels of CXCR4 in MSCs. It is worth noting that SDF-1 and its receptor CXCR4 are pivotal in MSCs-mediated cardiac repair [49-51]. The level of SDF-1 in the peri-infarcted myocardium was 


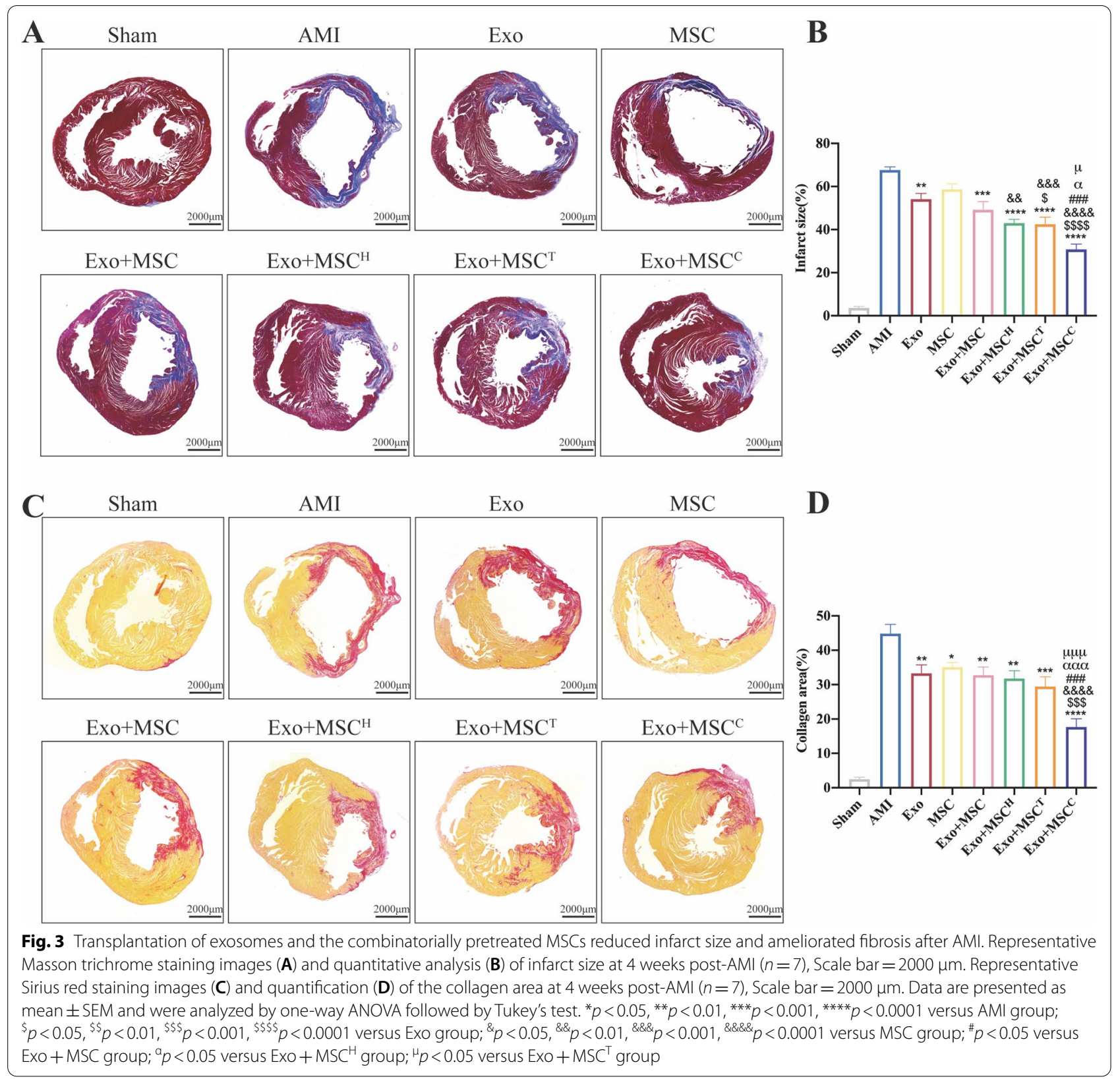

immediately upregulated and rapidly declined, while the elevated SDF-1 level facilitated the recruitment of $\mathrm{CXCR}^{+}$cells [25]. CXCR4, as the key receptor involved in MSCs recruitment to the infarcted myocardium, is a chemotactic receptor recognizing the chemokine SDF-1. Overexpression of CXCR4 in MSCs resulted in decreased LV remodeling and enhanced LV function, indicating that modifying the CXCR4 expression level was beneficial for post-infarction myocardial repair [67]. Since exosome delivery elevated the myocardial level of SDF-1, the upregulated CXCR4 level obtained with the combined pretreatment was beneficial for the recruitment of transplanted MSCs to the injured myocardium. For patients with AMI, early injection of exosomes could ameliorate the harsh microenvironment and prolong the therapeutic window for MSC transplantation. Although further large animal experiments and clinical trials are needed, this sequential transplantation approach provides novel insights into the clinical treatment of AMI.

Stem cell therapy is a promising strategy for augmenting myocardial repair, but its clinical use is highly restricted by the low retention and poor survival of 


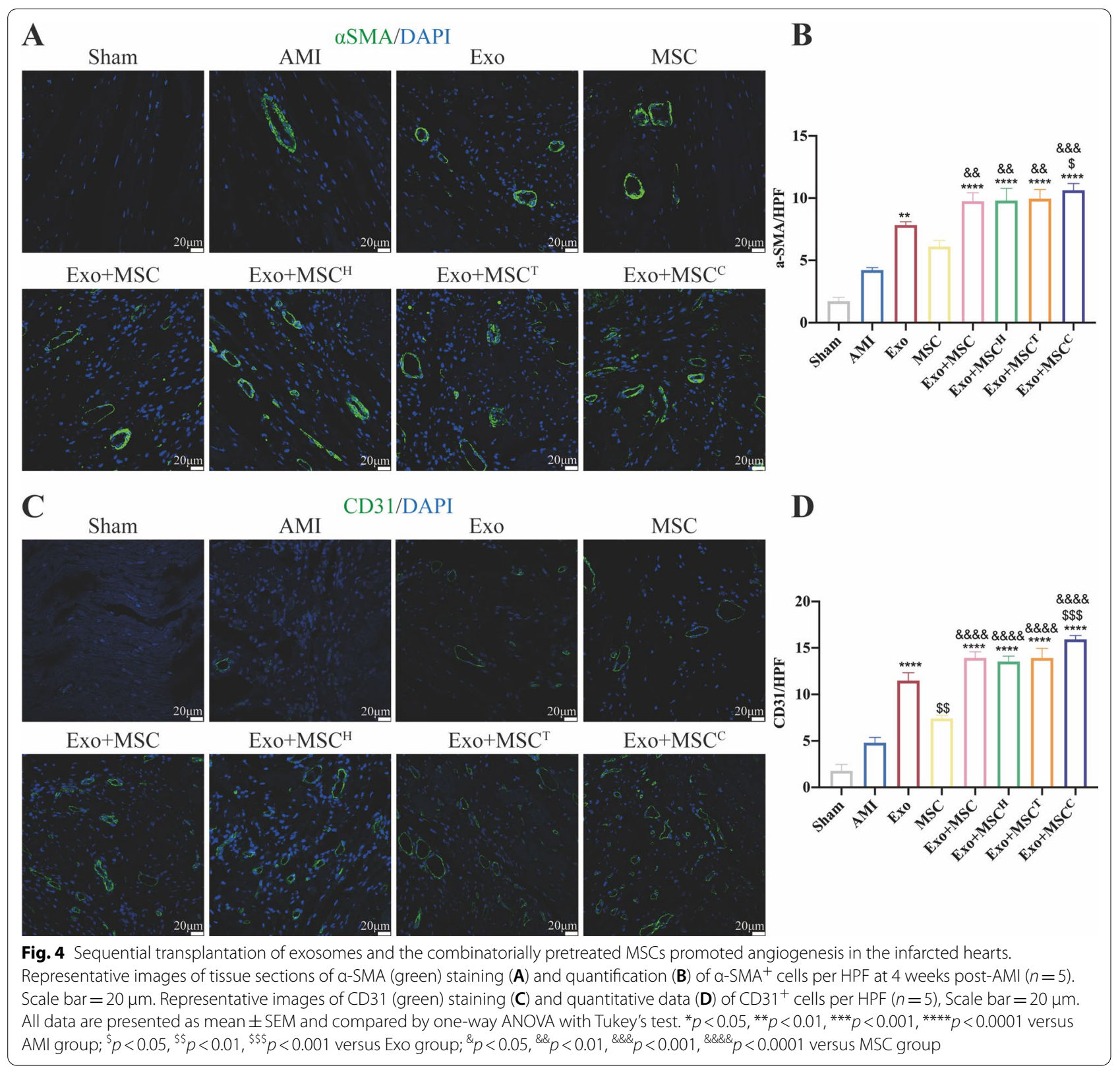

(See figure on next page.)

Fig. 5 Combined pretreatment with hypoxia and TXL elevated the expression level of CXCR4 and increased the retention rate of transplanted MSCs. Combined pretreatment with hypoxia and TXL elevated the retention rate of the transplanted MSCs in infarcted myocardium $(\mathbf{A}, \mathbf{B})(n=5)$. Scale bar $=50 \mu \mathrm{m}$. Combined pretreatment with hypoxia and TXL significantly elevated both the mRNA $(n=4)(\mathbf{C})$ and protein levels $(n=5)(\mathbf{D}, \mathbf{E})$ of CXCR4 in MSCs. After $24 \mathrm{~h}$ of incubation, PKH-26-labeled exosomes could be taken up by MSCs (F). Under H/SD conditions, exosomes effectively protected MSCs against apoptosis $(\mathbf{G}, \mathbf{H})(n=4)$. Representative images of western blotting $(\mathbf{I}, \mathbf{K})$ and quantitative data $(\mathbf{J}, \mathbf{L})$ of the protein levels of BCl-2 and cleaved-caspase $3(n=4)$. Statistical data were analyzed using one-way ANOVA followed by Tukey's test with data shown as mean \pm SEM.

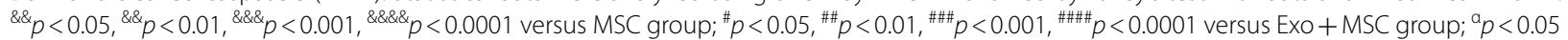
versus Exo + MSC ${ }^{\mathrm{H}}$ group; ${ }^{\delta \varphi \varphi \varphi \varphi} p<0.0001$ versus MSC ${ }^{\mathrm{H}}$ group; ${ }^{\varepsilon \varepsilon \varepsilon \varepsilon} p<0.0001$ versus MSC ${ }^{\top}$ group; ${ }^{\mu} p<0.05$ versus Exo + MSC $^{\top}$ group; ${ }^{*} p<0.05$, ${ }^{* *} p<0.01$ versus $\mathrm{H} / \mathrm{SD}$ group; $\$ p<0.05$ versus Exosome (ultra) group 


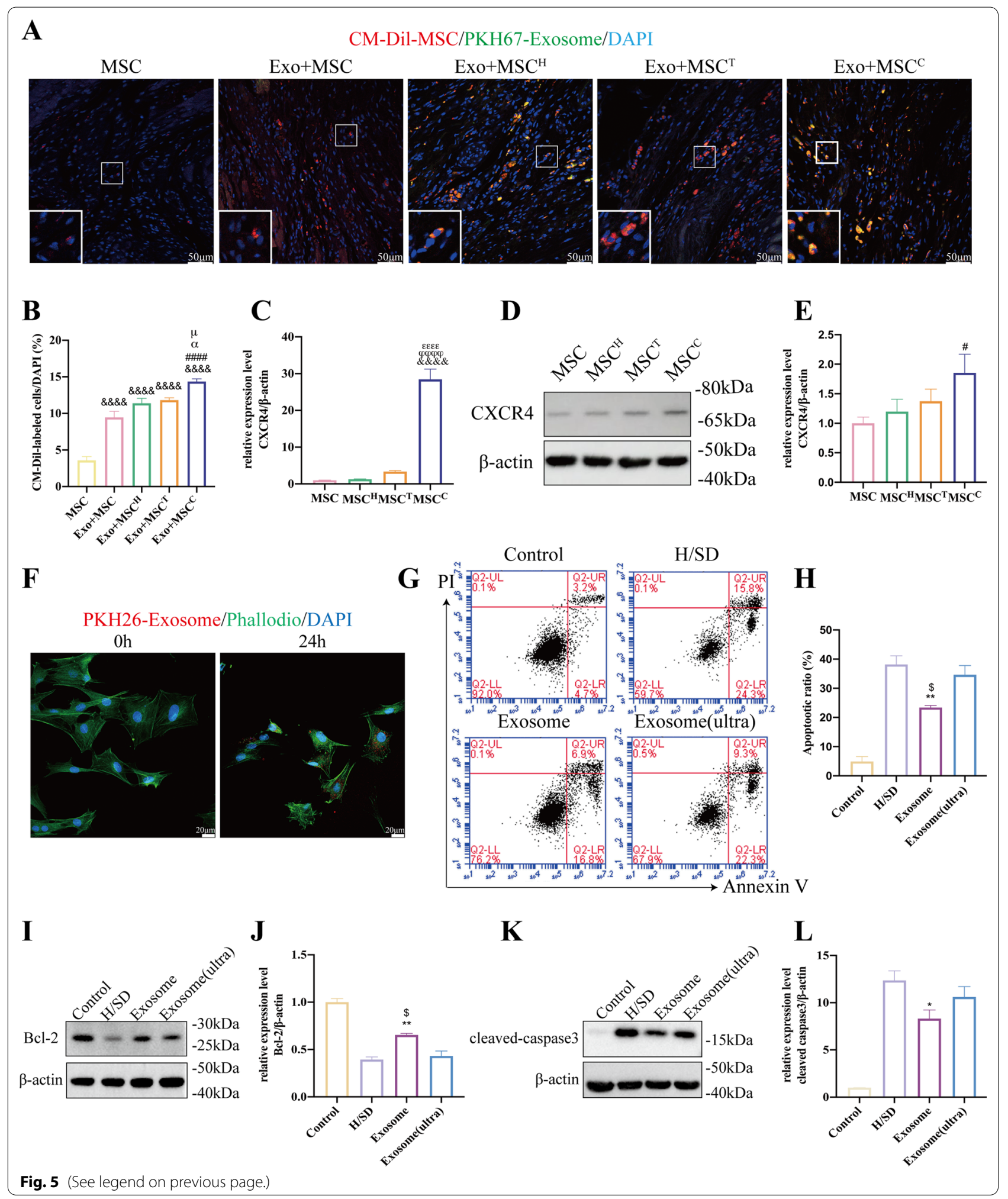

engrafted cells. In recent years, novel strategies, including MSCs modifications and combining cell therapy, have been developed to enhance the efficacy of stemcell-based therapy $[68,69]$. In this study, we found that sequential transplantation of exosomes and combinatorially pretreated MSCs further facilitated cardiac recovery. 


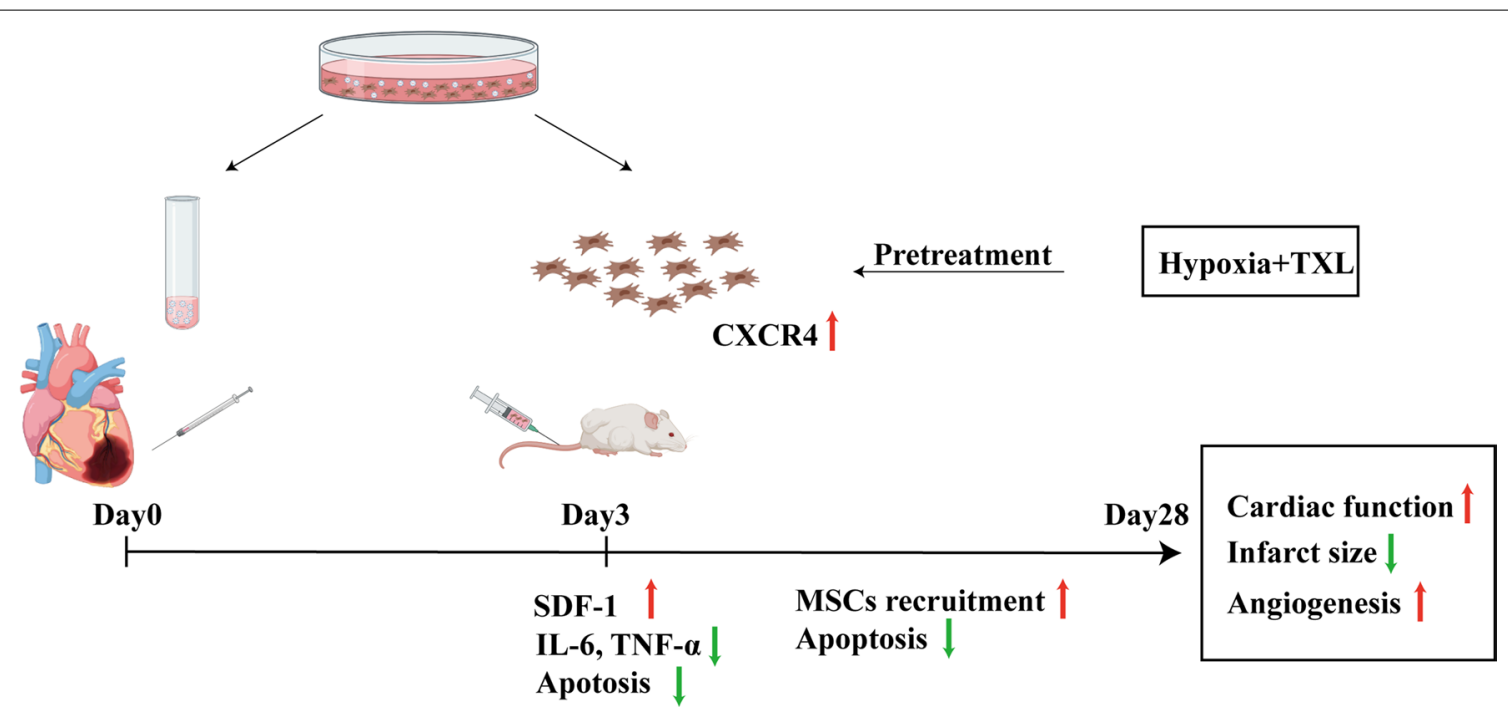

Fig. 6 Effects and mechanisms of sequential transplantation of exosomes and the combinatorially pretreated MSCs in the treatment of AMI. Delivery of exosomes into infarcted myocardium 30 min after infarction markedly elevated myocardial SDF-1 levels, decreased inflammatory cytokines levels including TNF- $a$ and IL-6 and reduced apoptosis at Day 3 post-AMI, ameliorating the harsh microenvironment which was beneficial for the recruitment and survival of the sequentially transplanted MSCs. In addition, combinatorial pretreatment of hypoxia and TXL augmented the CXCR4 level and increased the recruitment of transplanted MSCs to the infarcted myocardium. These effects ultimately led to significantly enhanced cardiac function, angiogenesis and reduced infarct size

Although the effects of cardiac repair remain to be examined in preclinical and clinical research, current advances have indicated the promising potential of stem cell therapy in facilitating cardiac repair post-ischemic injury. Considering the promising potential, continuous exploration to develop novel cell-based approaches, such as combining stem cells and exosomes with biomaterials, and combinational use of different stem cell types, might help to achieve better cardiac recovery.

\section{Conclusions}

Transplantation of exosomes and the combined pretreated MSCs in a sequential manner effectively facilitated cardiac repair post-AMI. Transplantation of exosomes into ischemic hearts 30 min postinfarction markedly modulated the ischemic milieu, including reducing the levels of inflammatory TNF- $\alpha$ and IL- 6 factors, elevating SDF-1 expression levels and promoting the survival of MSCs. The combined pretreatment with hypoxia and TXL effectively enhanced the expression level of CXCR4, thus achieving better performance in facilitating cardiac repair, which offers novel insights into stem cell-mediated cardiac repair.

\section{Abbreviations}

CVD: Cardiovascular disease; MI: Myocardial infarction; MSC: Mesenchymal stem cell; SDF-1: Stromal cell-derived factor 1; CXCR4: CXC chemokine receptor 4; TXL: Tongxinluo; SD: Sprague-Dawley; TEM: Transmission electron microscopy; NTA: Nanoparticle tracking analysis; LAD: Left anterior descending; LVEF: Left ventricular ejection fraction; LVFS: Left ventricular fractional shortening; LVEDV: Left ventricular end-diastolic volume; LVESV: Left ventricular end-systolic volume; cTNT: Cardiac troponin T; HPF: High-power fields; a-SMA: a-Smooth muscle actin; H/SD: Hypoxia and serum deprivation; QRT-PCR: Quantitative real-time polymerase chain reaction; SEM: Standard error of mean; LV: Left ventricle; CSC: Cardiac stem cells.

\section{Acknowledgements}

We thank Jian Meng, Hao Li and Shuo Gao in the State Key Laboratory of Cardiovascular Disease for their technical assistance.

\section{Authors' contributions}

$Y X$ and RT contributed to the study design, data collection and manuscript writing. JX, WJ, ZG, LZ, XL and YN performed the data analysis. PH, JX, GC, CJ, $X \mathrm{~L}, \mathrm{HQ}$ and $\mathrm{YY}$ contributed to the edit of the manuscript. All authors read and approved the final manuscript.

\section{Funding}

This project was supported by grants from the National Key Research and Development Program of China (No.2017YFC1700503), CAMS Innovation Fund for Medical Sciences (CIFMS) (2016-12M-1-009), and the National Natural Science Foundation of China (No. 81573957, No. 81774292, No. 81874461, No. 82070307).

\section{Availability of data and materials}

All data generated or analyzed during this study are included in this published article.

\section{Declarations}

Ethics approval and consent to participate

All animal experiments were approved by the Institutional Animal Care and Use Committee of Fuwai Hospital, Chinese Academy of Medical Sciences and Peking Union Medical College.

\section{Consent for publication}

Not applicable. 


\section{Competing interests}

The authors declare that they have no competing interests.

Received: 29 August 2021 Accepted: 17 December 2021 Published online: 07 February 2022

\section{References}

1. Benjamin EJ, Muntner P, Alonso A, Bittencourt MS, Callaway CW, Carson AP, et al. Heart Disease and Stroke Statistics - 2019 update: a report from the American Heart Association. Circulation. 2019;139(10):e56-528.

2. Roth GA, Johnson C, Abajobir A, Abd-Allah F, Abera SF, Abyu G, et al. Global, regional, and national burden of cardiovascular diseases for 10 causes, 1990 to 2015. J Am Coll Cardiol. 2017;70(1):1-25.

3. James SL, Abate D, Abate KH, Abay SM, Abbafati C, Abbasi N, Abbastabar $\mathrm{H}$, Abd-Allah F, Abdela J, Abdelalim A, Abdollahpour I. Global, regional, and national incidence, prevalence, and years lived with disability for 354 diseases and injuries for 195 countries and territories, 1990-2017: a systematic analysis for the Global Burden of Disease Study 2017. Lancet. 2018;392(10159):1789-858.

4. Prabhu SD, Frangogiannis NG. The biological basis for cardiac repair after myocardial infarction: from inflammation to fibrosis. Circ Res. 2016;119(1):91-112.

5. Frangogiannis NG. The inflammatory response in myocardial injury, repair, and remodelling. Nat Rev Cardiol. 2014;11(5):255-65.

6. Mathur A, Martin JF. Stem cells and repair of the heart. Lancet. 2004;364(9429):183-92.

7. Tongers J, Losordo DW, Landmesser U. Stem and progenitor cell-based therapy in ischaemic heart disease: promise, uncertainties, and challenges. Eur Heart J. 2011;32(10):1197-206.

8. Faiella W, Atoui R. Therapeutic use of stem cells for cardiovascular disease. Clin Transl Med. 2016;5(1):34.

9. Williams AR, Hare JM. Mesenchymal stem cells: biology, pathophysiology, translational findings, and therapeutic implications for cardiac disease. Circ Res. 2011;109(8):923-40.

10. Zimmet JM, Hare JM. Emerging role for bone marrow derived mesenchymal stem cells in myocardial regenerative therapy. Basic Res Cardiol. 2005;100(6):471-81.

11. Guo Y, Yu Y, Hu S, Chen Y, Shen Z. The therapeutic potential of mesenchymal stem cells for cardiovascular diseases. Cell Death Dis. 2020;11(5):349.

12. Barbash IM, Chouraqui P, Baron J, Feinberg MS, Etzion S, Tessone A, et al. Systemic delivery of bone marrow-derived mesenchymal stem cells to the infarcted myocardium: feasibility, cell migration, and body distribution. Circulation. 2003;108(7):863-8.

13. Feyen DAM, Gaetani R, Doevendans PA, Sluijter JPG. Stem cell-based therapy: improving myocardial cell delivery. Adv Drug Deliv Rev. 2016;106(Pt A):104-15.

14. Chen Z, Chen L, Zeng C, Wang WE. Functionally improved mesenchymal stem cells to better treat myocardial infarction. Stem Cells Int. 2018;2018:7045245.

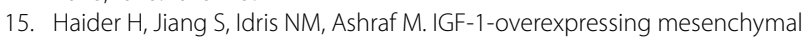
stem cells accelerate bone marrow stem cell mobilization via paracrine activation of SDF-1alpha/CXCR4 signaling to promote myocardial repair. Circ Res. 2008;103(11):1300-8.

16. Zimmermann JA, Hettiaratchi MH, McDevitt TC. Enhanced immunosuppression of $T$ cells by sustained presentation of bioactive interferon- $\gamma$ within three-dimensional mesenchymal stem cell constructs. Stem Cells Transl Med. 2017;6(1):223-37.

17. Dong F, Harvey J, Finan A, Weber K, Agarwal U, Penn MS. Myocardial CXCR4 expression is required for mesenchymal stem cell mediated repair following acute myocardial infarction. Circulation. 2012;126(3):314-24.

18. Mayorga ME, Kiedrowski M, McCallinhart P, Forudi F, Ockunzzi J, Weber K, et al. Role of SDF-1:CXCR4 in impaired post-myocardial infarction cardiac repair in diabetes. Stem Cells Transl Med. 2018;7(1):115-24.

19. Penn MS, Pastore J, Miller T, Aras R. SDF-1 in myocardial repair. Gene Ther. 2012;19(6):583-7.

20. Hu X, Dai S, Wu WJ, Tan W, Zhu X, Mu J, et al. Stromal cell derived factor-1 alpha confers protection against myocardial ischemia/reperfusion injury: role of the cardiac stromal cell derived factor-1 alpha CXCR4 axis. Circulation. 2007;116(6):654-63.
21. Liu X, Duan B, Cheng Z, Jia X, Mao L, Fu H, et al. SDF-1/CXCR4 axis modulates bone marrow mesenchymal stem cell apoptosis, migration and cytokine secretion. Protein Cell. 2011;2(10):845-54.

22. Penn MS. Importance of the SDF-1:CXCR4 axis in myocardial repair. Circ Res. 2009;104(10):1133-5.

23. Saxena A, Fish JE, White MD, Yu S, Smyth JW, Shaw RM, et al. Stromal cell-derived factor-1alpha is cardioprotective after myocardial infarction. Circulation. 2008;117(17):2224-31.

24. Ma J, Ge J, Zhang S, Sun A, Shen J, Chen L, et al. Time course of myocardial stromal cell-derived factor 1 expression and beneficial effects of intravenously administered bone marrow stem cells in rats with experimental myocardial infarction. Basic Res Cardiol. 2005;100(3):217-23.

25. Abbott JD, Huang Y, Liu D, Hickey R, Krause DS, Giordano FJ. Stromal cellderived factor-1alpha plays a critical role in stem cell recruitment to the heart after myocardial infarction but is not sufficient to induce homing in the absence of injury. Circulation. 2004;110(21):3300-5.

26. Pegtel DM, Gould SJ. Exosomes. Annu Rev Biochem. 2019;88:487-514.

27. Kalluri R, LeBleu VS. The biology, function, and biomedical applications of exosomes. Science. 2020;367(6478):eaau6977.

28. Cheng H, Chang S, Xu R, Chen L, Song X, Wu J, et al. Hypoxia-challenged MSC-derived exosomes deliver miR-210 to attenuate post-infarction cardiac apoptosis. Stem Cell Res Ther. 2020;11(1):224.

29. Zhu LP, Tian T, Wang JY, He JN, Chen T, Pan M, et al. Hypoxia-elicited mesenchymal stem cell-derived exosomes facilitates cardiac repair through miR-125b-mediated prevention of cell death in myocardial infarction. Theranostics. 2018;8(22):6163-77.

30. Xiao C, Wang K, Xu Y, Hu H, Zhang N, Wang Y, et al. Transplanted mesenchymal stem cells reduce autophagic flux in infarcted hearts via the exosomal transfer of miR-125b. Circ Res. 2018;123(5):564-78.

31. Wen Z, Mai Z, Zhu X, Wu T, Chen Y, Geng D, et al. Mesenchymal stem cell-derived exosomes ameliorate cardiomyocyte apoptosis in hypoxic conditions through microRNA144 by targeting the PTEN/AKT pathway. Stem Cell Res Ther. 2020;11(1):36.

32. Zhao J, Li X, Hu J, Chen F, Qiao S, Sun X, et al. Mesenchymal stromal cellderived exosomes attenuate myocardial ischaemia-reperfusion injury through miR-182-regulated macrophage polarization. Cardiovasc Res. 2019;115(7):1205-16.

33. Chen Y, Zhao Y, Chen W, Xie L, Zhao ZA, Yang J, et al. MicroRNA-133 overexpression promotes the therapeutic efficacy of mesenchymal stem cells on acute myocardial infarction. Stem Cell Res Ther. 2017;8(1):268.

34. Sun X, Shan A, Wei Z, Xu B. Intravenous mesenchymal stem cell-derived exosomes ameliorate myocardial inflammation in the dilated cardiomyopathy. Biochem Biophys Res Commun. 2018;503(4):2611-8.

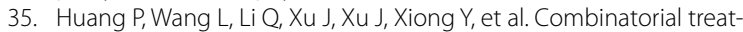
ment of acute myocardial infarction using stem cells and their derived exosomes resulted in improved heart performance. Stem Cell Res Ther. 2019;10(1):300

36. Xu J, Xiong YY, Li Q, Hu MJ, Huang PS, Xu JY, et al. Optimization of timing and times for administration of atorvastatin-pretreated mesenchymal stem cells in a preclinical model of acute myocardial infarction. Stem Cells Transl Med. 2019;8(10):1068-83.

37. Li N, Yang YJ, Qian HY, Li Q, Zhang Q, Li XD, et al. Intravenous administration of atorvastatin-pretreated mesenchymal stem cells improves cardiac performance after acute myocardial infarction: role of CXCR4. Am J Transl Res. 2015;7(6):1058-70.

38. Hu X, Wu R, Jiang Z, Wang $L$, Chen $P$, Zhang $L$, et al. Leptin signaling is required for augmented therapeutic properties of mesenchymal stem cells conferred by hypoxia preconditioning. Stem Cells. 2014;32(10):2702-13.

39. Li Q, Dong QT, Yang YJ, Tian XQ, Jin C, Huang PS, et al. AMPK-mediated cardioprotection of atorvastatin relates to the reduction of apoptosis and activation of autophagy in infarcted rat hearts. Am J Transl Res. 2016;8(10):4160-71.

40. Sun J, Shen H, Shao L, Teng X, Chen Y, Liu X, et al. HIF-1 a overexpression in mesenchymal stem cell-derived exosomes mediates cardioprotection in myocardial infarction by enhanced angiogenesis. Stem Cell Res Ther. 2020;11(1):373.

41. Deuse T, Peter C, Fedak PW, Doyle T, Reichenspurner H, Zimmermann WH, et al. Hepatocyte growth factor or vascular endothelial growth factor gene transfer maximizes mesenchymal stem cell-based myocardial 
salvage after acute myocardial infarction. Circulation. 2009;120(11 Suppl):S247-54.

42. Huang J, Zhang Z, Guo J, Ni A, Deb A, Zhang L, et al. Genetic modification of mesenchymal stem cells overexpressing CCR1 increases cell viability, migration, engraftment, and capillary density in the injured myocardium. Circ Res. 2010;106(11):1753-62.

43. You Y, Kobayashi K, Colak B, Luo P, Cozens E, Fields L, et al. Engineered cell-degradable poly(2-alkyl-2-oxazoline) hydrogel for epicardial placement of mesenchymal stem cells for myocardial repair. Biomaterials. 2021;269:120356.

44. Choe G, Kim SW, Park J, Park J, Kim S, Kim YS, et al. Anti-oxidant activity reinforced reduced graphene oxide/alginate microgels: mesenchymal stem cell encapsulation and regeneration of infarcted hearts. Biomaterials. 2019;225:119513.

45. Li N, Yang YJ, Cui HH, Zhang Q, Jin C, Qian HY, et al. Tongxinluo decreases apoptosis of mesenchymal stem cells concentration-dependently under hypoxia and serum deprivation conditions through the AMPKVNOS pathway. J Cardiovasc Pharmacol. 2014;63(3):265-73.

46. Jaussaud J, Biais M, Calderon J, Chevaleyre J, Duchez P, Ivanovic Z, et al. Hypoxia-preconditioned mesenchymal stromal cells improve cardiac function in a swine model of chronic myocardial ischaemia. Eur J Cardiothorac Surg. 2013;43(5):1050-7.

47. Théry C, Amigorena S, Raposo G, Clayton A. Isolation and characterization of exosomes from cell culture supernatants and biological fluids. Curr Protoc Cell Biol. 2006;30:3-22.

48. Tang R, Wang K, Xiong Y, Meng J, Yang Y. A fluorescence assay for evaluating the permeability of a cardiac microvascular endothelial barrier in a rat model of ischemia/reperfusion. J Vis Exp. 2021;172:e62746.

49. Ghadge SK, Mühlstedt S, Ozcelik C, Bader M. SDF-1a as a therapeutic stem cell homing factor in myocardial infarction. Pharmacol Ther. 2011;129(1):97-108.

50. Askari AT, Unzek S, Popovic ZB, Goldman CK, Forudi F, Kiedrowski $M$, et al. Effect of stromal-cell-derived factor 1 on stem-cell homing and tissue regeneration in ischaemic cardiomyopathy. Lancet. 2003:362(9385):697-703.

51. Misao Y, Takemura G, Arai M, Ohno T, Onogi H, Takahashi T, et al. Importance of recruitment of bone marrow-derived CXCR4+ cells in post-infarct cardiac repair mediated by G-CSF. Cardiovasc Res. 2006;71(3):455-65.

52. Barile L, Moccetti T, Marbán E, Vassalli G. Roles of exosomes in cardioprotection. Eur Heart J. 2017;38(18):1372-9.

53. Sahoo S, Losordo DW. Exosomes and cardiac repair after myocardial infarction. Circ Res. 2014;114(2):333-44.

54. Wei Z, Qiao S, Zhao J, Liu Y, Li Q, Wei Z, et al. miRNA-181a over-expression in mesenchymal stem cell-derived exosomes influenced inflammatory response after myocardial ischemia-reperfusion injury. Life Sci. 2019;232:116632

55. Ma T, Chen Y, Chen Y, Meng Q, Sun J, Shao L, et al. MicroRNA-132, delivered by mesenchymal stem cell-derived exosomes, promote angiogenesis in myocardial infarction. Stem Cells Int. 2018;2018:3290372.

56. Kang K, Ma R, Cai W, Huang W, Paul C, Liang J, et al. Exosomes secreted from CXCR4 overexpressing mesenchymal stem cells promote cardioprotection via Akt signaling pathway following myocardial infarction. Stem Cells Int. 2015;2015:659890.

57. Kishore R, Khan M. More than tiny sacks: stem cell exosomes as cell-free modality for cardiac repair. Circ Res. 2016;118(2):330-43.

58. Zhang Z, Yang J, Yan W, Li Y, Shen Z, Asahara T. Pretreatment of cardiac stem cells with exosomes derived from mesenchymal stem cells enhances myocardial repair. J Am Heart Assoc. 2016;5(1):e002856.

59. Shi B, Wang Y, Zhao R, Long X, Deng W, Wang Z. Bone marrow mesenchymal stem cell-derived exosomal miR-21 protects C-kit+ cardiac stem cells from oxidative injury through the PTEN/PI3K/Akt axis. PLOS ONE. 2018;13(2):e0191616.

60. Guo R, Wan F, Morimatsu M, Xu Q, Feng T, Yang H, et al. Cell sheet formation enhances the therapeutic effects of human umbilical cord mesenchymal stem cells on myocardial infarction as a bioactive material. Bioact Mater. 2021;6(9):2999-3012.

61. Shimizu T, Yamato M, Kikuchi A, Okano T. Two-dimensional manipulation of cardiac myocyte sheets utilizing temperature-responsive culture dishes augments the pulsatile amplitude. Tissue Eng. 2001;7(2):141-51.
62. Christman KL, Lee RJ. Biomaterials for the treatment of myocardial infarction. J Am Coll Cardiol. 2006;48(5):907-13.

63. Matsuura K, Haraguchi Y, Shimizu T, Okano T. Cell sheet transplantation for heart tissue repair. J Control Release. 2013;169(3):336-40.

64. Liu H, Xue W, Ge G, Luo X, Li Y, Xiang H, et al. Hypoxic preconditioning advances CXCR4 and CXCR7 expression by activating HIF-1a in MSCs. Biochem Biophys Res Commun. 2010;401(4):509-15.

65. Wang JA, Chen TL, Jiang J, Shi H, Gui C, Luo RH, et al. Hypoxic preconditioning attenuates hypoxia/reoxygenation-induced apoptosis in mesenchymal stem cells. Acta Pharmacol Sin. 2008;29(1):74-82.

66. Bader AM, Klose K, Bieback K, Korinth D, Schneider M, Seifert M, et al. Hypoxic preconditioning increases survival and pro-angiogenic capacity of human cord blood mesenchymal stromal cells in vitro. PLoS ONE. 2015;10(9):e0138477.

67. Cheng Z, Ou L, Zhou X, Li F, Jia X, Zhang Y, et al. Targeted migration of mesenchymal stem cells modified with CXCR4 gene to infarcted myocardium improves cardiac performance. Mol Ther. 2008;16(3):571-9.

68. Bagno L, Hatzistergos KE, Balkan W, Hare JM. Mesenchymal stem cellbased therapy for cardiovascular disease: progress and challenges. Mol Ther. 2018;26(7):1610-23.

69. Beliën H, Evens L, Hendrikx M, Bito V, Bronckaers A. Combining stem cells in myocardial infarction: the road to superior repair? Med Res Rev. 2021;42:343-73.

\section{Publisher's Note}

Springer Nature remains neutral with regard to jurisdictional claims in published maps and institutional affiliations.
Ready to submit your research? Choose BMC and benefit from:

- fast, convenient online submission

- thorough peer review by experienced researchers in your field

- rapid publication on acceptance

- support for research data, including large and complex data types

- gold Open Access which fosters wider collaboration and increased citations

- maximum visibility for your research: over $100 \mathrm{M}$ website views per year

At BMC, research is always in progress.

Learn more biomedcentral.com/submissions 